\title{
Clinical Presentations of 176 Cases of Primary Central Nervous System Lymphoma: A Case Series
}

\author{
Farzad Ashrafi, ${ }^{1,2}$ Alireza Zali, ${ }^{2}$ Marzieh Amiri, ${ }^{3}$ and Fatemeh Shabani ${ }^{1,}$ \\ ${ }^{1}$ Department of Neurology, Shohadaye Tajrish Hospital, Shahid Beheshti University of Medical Sciences, Tehran, IR Iran \\ ${ }^{2}$ Functional Neurosurgery Research Center, Shohadaye Tajrish Hospital, Shahid Beheshti University of Medical Sciences, Tehran, IR Iran \\ ${ }^{3}$ Department of Emergency Medicine, Shahid Beheshti Hospital, Guilan University of Medical Sciences, Anzali, IR Iran \\ "Corresponding author: Fatemeh Shabani, Department of Neurology, Shohadaye Tajrish Hospital, Tajrish Square, Tehran, IR Iran. Tel: +98-9121579198, Fax: +98-2122721155, E-mail: \\ dr.fatemeshabani@gmail.com
}

Received 2015 August 04; Revised 2015 August 19; Accepted 2015 September 08.

\begin{abstract}
Background: Primary central nervous system lymphoma (PCNSL) is a malignant tumor, the incidence of which has been increasing in immune compromised patients during the last two decades.

Objectives: This study was conducted to determine the most prevalent clinical presenting symptoms of PCNSL patients.

Patients and Methods: In this retrospective descriptive study, all PCNSL patients' data over a 25-year period (1990-2014) were assessed. PCNSL was confirmed pathologically after stereotactic biopsy in the Neurosurgery Department of Shohadaye Tajrish Hospital, Tehran, Iran.

Results: A total of 176 cases of PCNSL were enrolled. There were 107 (60.8\%) male patients, with a 1.5:1 male: female ratio. The patients most commonly presented in the sixth decade of their lives, with a mean age of $47 \pm 1.5$ years. The most common presenting symptoms were hemiparesis (56.2\%) and headache (51.7\%). The periventricular white matter (51.1\%) and basal ganglion (48.9\%) were the most common sites of involvement, and they frequently affected the supratentorial area $(84.7 \%)$.

Conclusions: Based on the data from this study, hemiparesis and headache were the most prevalent clinical presenting symptoms of PCNSL. Cognitive impairment and personality changes were also common in these patients.
\end{abstract}

Keywords: Central Nervous System, Lymphoma, Neurologic Manifestations

\section{Background}

Primary central nervous system lymphoma (PCNSL) is a highly aggressive B-cell lymphoma. It is a type of non-Hodgkin lymphoma that commonly originates in the brain parenchyma, spinal cord, cranial nerves, leptomeninges, and eyes. It is limited to the central nervous system (CNS), without any systemic involvement (1-4). Based on the available data, during the past two decades, the incidence of PCNSL has increased in immune compromised patients, including those with acquired immune deficiency syndrome (AIDS) (5-7). Some investigators have mentioned that although the overall incidence of PCNSL is rising in immune competent patients over the age of 60 years, the application of highly active antiretroviral therapy against Epstein-Barr virus infections has led to a decreased incidence of AIDS-related PCNSL (8). However, PCNSL is still the most common brain tumor in AIDS patients, 2\%-13\% of whom are affected during the course of their disease (4, 9-12). PCNSL can occur in all age groups, but the highest prevalence was reported in the fifth to seventh decades of non-AIDS patients' lives (12).

PCNSL tumors usually involve the supratentorial brain parenchyma, but symptoms often are widespread and multifocal (13). Due to widespread growth and the infiltrative nature of the disease, symptoms mainly include cognitive impairment, disorientation, slow psychomotor activity, and personality changes (13-15). Seizures develop in $2 \%-33 \%$ of patients during the course of the disease, with a higher seizure incidence in AIDS patients (16).

PCNSL is a challenge for physicians and researchers because of its increased incidence, specific clinical importance, and poorly understood pathobiology. Limited clinical studies and a lack of sufficient information lead to the poor prognosis for this disease, with a mean survival of 10-20 months (2). There are several published manuscripts on different aspects of PCNSL, but almost all were prepared with small sample sizes.

\section{Objectives}

This study was conducted to determine the most prevalent clinical presenting symptoms of PCNSL patients referred to Shohadaye Tajrish Medical Center over a 25-year period.

Copyright @ 2015, Tehran University of Medical Sciences. This is an open-access article distributed under the terms of the Creative Commons Attribution-NonCommercial 4.0 International License (http://creativecommons.org/licenses/by-nc/4.0/) which permits copy and redistribute the material just in noncommercial usages, provided the original work is properly cited. 


\section{Patients and Methods}

In this cross-sectional retrospective study, the records of all PCNSL patients admitted to the neurosurgery department of Shohadaye Tajrish Hospital in Tehran, Iran, during a 25-year period (1990-2014) were assessed. PCNSL was confirmed pathologically after stereotactic biopsy in the neurosurgery department. There were no exclusion criteria except for defective files, if any. Data were collected from the archive of the Functional Neurosurgery Research Center at Shohadaye Tajrish Hospital. This center is one of the largest referral centers for stereotactic procedures in Iran, admitting hundreds of patients annually and saving the required data for various topics of investigation.

This study was approved by the ethics committee of Shahid Beheshti University of Medical Sciences, and the researchers adhered to the principles of the Helsinki Declaration. Variables included the demographic data and the clinical presenting symptoms (hemiparesis, headache, personality and cognitive disorders, seizures, ataxia, and aphasia). Statistical analysis was performed with SPSS version 18. The results were calculated as percentages and quantitative frequencies, and are presented as mean \pm standard deviation (SD) and with diagrams.

\section{Results}

A total of 176 cases of PCNSL were enrolled. There were $107(60.8 \%)$ males and 69 (39.2\%) females, with a 1.5:1 male: female ratio. The mean age was $47 \pm 1.5$ years. The highest tumor incidence was during the sixth decade of life, followed by the seventh and fifth decades, respectively (Figure 1).

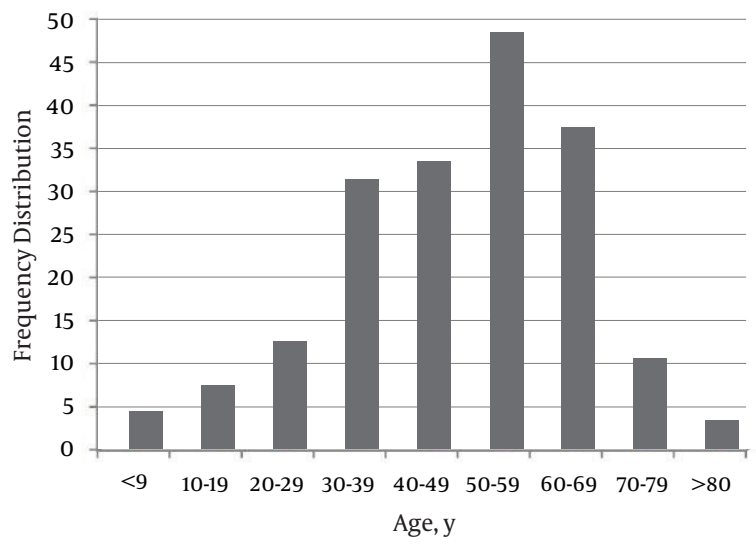

Figure 1. Frequency Distribution of PCNSL According to Patient Age
The most common presenting symptoms were hemiparesis (56.2\%), headache (51.7\%), personality disorders and cognitive impairment (26.7\%), seizure (12.5\%), cranial nerve palsy (10.8\%), ataxia (9.7\%), aphasia (9.1\%), and eye involvement $(4 \%$ ), respectively (Figure 2 ).

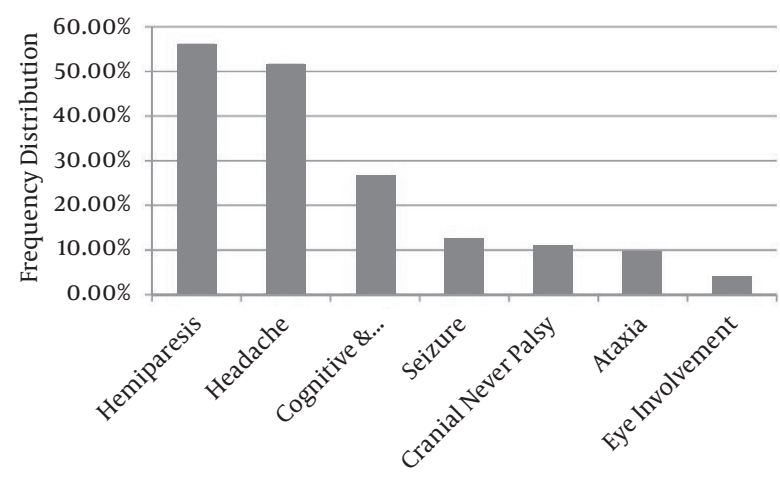

Figure 2. Clinical Symptom Frequency Distribution in PCNSL

Based on imaging findings, the periventricular white matter (51.1\%) and basal ganglion (48.9\%) were the most common sites of involvement (Figure 3).

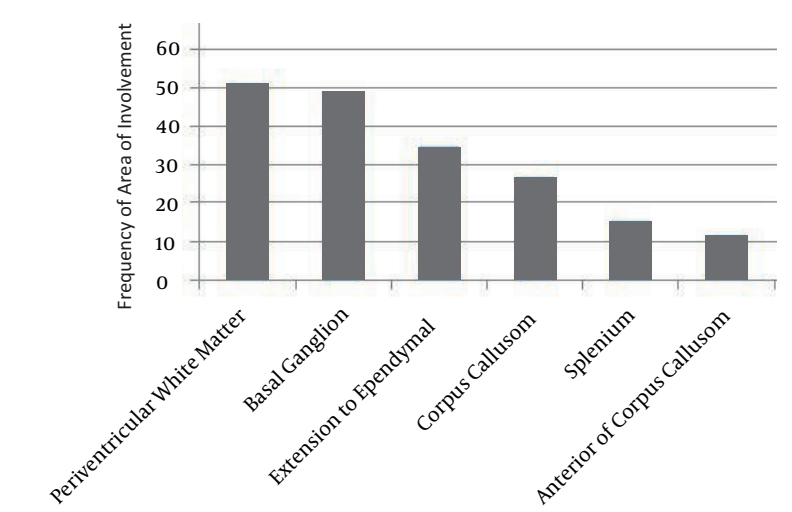

Figure 3. Frequency of Area of Involvement Based on Imaging Findings of PCNSL Patients

The PCNSL tumors more commonly affected the supratentorial area (84.7\%) compared to the subtentorial region (5.1\%). Among all cases, $10.2 \%$ had both supratentorial and subtentorial involvement (Figure 4).

\section{Discussion}

Hemiparesis and headache were the most prevalent clinical presenting symptoms among all of the PCNSL pa- 


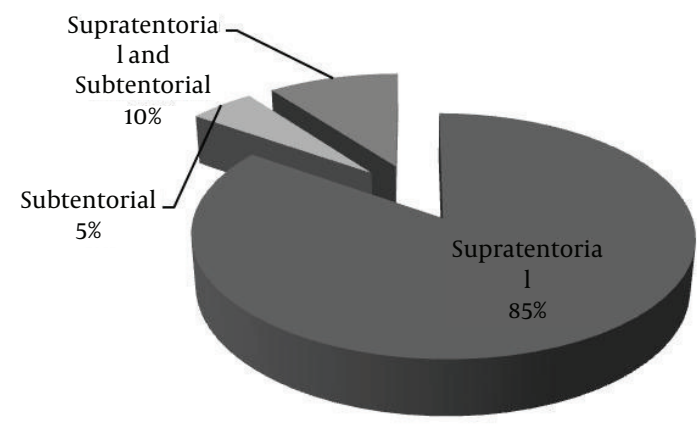

Figure 4. Frequency of Involvement Based on the Location of PCNSL Relative to the Tentorium

tients admitted to the Neurosurgery Department of Shohadaye Tajrish Hospital over the 25-year period of 1999-2014. Most research on this topic has been performed on small sample sizes, but this study benefitted from a comparatively larger sample size $(17,18)$. The demographic results, including mean age and the male-to-female ratio, were similar to those of studies by Makino et al. in 2006 and Rubenstein et al. in $2008(19,20)$. Our study showed that the highest prevalence of PCNSL is in the sixth decade of life; this finding is also compatible with other studies (21, 22). As reported as the main result of our study, Rubenstein et al. and Bhagavathi et al., in two separate studies in 2008, also found that sensory and motor symptoms were the most prevalent clinical presenting symptoms of PCNSL patients $(20,22)$. Rubenstein reported headaches in $55 \%$ and personality changes in $30 \%$ of patients. On the other hand, neuropsychiatric symptoms (43\%) and headache (33\%) were more common in the Bhagavathi et al. study. This is also compatible with the findings of Zali et al. in a study conducted in Iran in 2006 (21). In line with the findings of Kuker et al., periventricular white matter involvement was the most common site of tumor placement (23). In our study, $84.7 \%$ of PCNSLs involved the supratentorial area of the brain, which was the same as Bataille et al.'s findings in 2000 (24). Although PCNSL is rare, it most commonly presents in the fifth to sixth decades, with sensory and motor symptoms combined with headaches in the supratentorial region, involving the periventricular white matter and basal ganglia.

Some authors believe that the clinical presentation of PCNSL can differ between immunocompromised and immunocompetent patients (25). Therefore, a properly designed study based on this claim can be valuable. In the current study, only six immunocompromised patients were enrolled, so a statistical comparison was practically impossible. Based on the published literature, it seems that the incidence of PCNSL increases in immunocompetent individuals over 60 years old. However, interestingly, the total incidence has decreased in immunocompromised patients. It was reported that effective antiretroviral therapy against Epstein-Barr virus, considered one of the most important prorogating factors of PCNSL occurrence in HIV patients, would be effective in this manner (8). Overall, it can be concluded that the incidence of PCNSL is increasing and further research into this rare malignancy is still needed.

\subsection{Implications for Future Research}

The basic information that must be evaluated in a welldesigned epidemiologic study include the clinical course of the patients, possible complications after stereotactic biopsy, postoperative computed tomography findings, rate of second biopsy implication, sampling errors, problems with histopathological diagnoses, rate of immunohistochemistry implications to prove diagnoses, adjuvant therapies, success rates of treatments, tumor-control intervals, and overall survival of the patients.

\subsection{Conclusions}

This study emphasizes that the clinical symptoms of PCNSL are not specific and, as with other intracranial tumors, sensory and motor symptoms are the most common. Based on data from this study, most PCNSL patients are males in the sixth decade of life. Hemiparesis and headache were the most prevalent clinical presenting symptoms of PCNSL patients, and cognitive impairment and personality changes were also common.

\section{Acknowledgments}

We would like to express our special thanks to the staff of the Neurology and Neurosurgery Department at Shohadaye Tajrish Hospital, Tehran, Iran.

\section{Footnotes}

Authors' Contribution: Farzad Ashrafi and Alireza Zali contributed in study design. Fatemeh Shabani performed data acquisition. Marzieh Amiri enrolled in data analysis and interpretation. Fatemeh Shabani, Farzad Ashrafi and Alireza Zali wrote the draft; and Marzieh Amiri revised it critically for important intellectual content. All authors approved the final version and are responsible for all aspects of the work. 
Funding/Support: All authors declare that this study was accomplished without any funding or support, and the authors were responsible for all expenses. This study was a part of Dr. Fatemeh Shaabani's thesis for a Neurology Residency at Shahid Beheshti University of Medical Sciences, Tehran, Iran.

\section{References}

1. Paulus W. Classification, pathogenesis and molecular pathology of primary CNS lymphomas. J Neurooncol. 1999;43(3):203-8. [PubMed: 10563424].

2. Sheibani K, Battifora H, Winberg CD, Burke JS, Ben-Ezra J, Ellinger GM, et al. Further evidence that "malignant angioendotheliomatosis" is an angiotropic large-cell lymphoma. $N$ Engl J Med. 1986;314(15):943-8. doi: 10.1056/NEJM198604103141502. [PubMed: 3485768].

3. Torenbeek R, Scheltens P, Strack van Schijindel RJ, Algra PR, Heimans JJ, van der Valk P. Angiotropic intravascular large-cell lymphoma with massive cerebral extension. J Neurol Neurosurg Psychiatry. 1993;56(8):914-6. [PubMed: 8350112].

4. Gerstner ER, Batchelor TT. In: Primary Central Nervous System Tumors. Norden AD, Reardon DA, Wen PCY, editors. Humana Press; 2011 pp. 333-53.Primary Central Nervous System Lymphoma.

5. Beral V, Peterman T, Berkelman R, Jaffe H. Originally published as Volume 1, Issue 8745AIDS-associated non-Hodgkin lymphoma. The Lancet. 1991;337(8745):805-9. doi: 10.1016/0140-6736(91)92513-2.

6. Cote TR, Manns A, Hardy CR, Yellin FJ, Hartge P. Epidemiology of brain lymphoma among people with or without acquired immunodeficiency syndrome. AIDS/Cancer Study Group. J Natl Cancer Inst. 1996;88(10):675-9. [PubMed: 8627644].

7. Eby NL, Grufferman S, Flannelly CM, Schold SC, Vogel FS, Burger PC. Increasing incidence of primary brain lymphoma in the US. Cancer. 1988;62(11):2461-5. [PubMed: 3179963].

8. Batara JF, Grossman SA. Primary central nervous system lymphomas. Curr Opin Neurol. 2003;16(6):671-5. doi: 10.1097/01.wco.0000102624.38669.2b. [PubMed: 14624075].

9. Camilleri-Broet S, Davi F, Feuillard J, Seilhean D, Michiels JF, Brousset $\mathrm{P}$, et al. AIDS-related primary brain lymphomas: histopathologic and immunohistochemical study of 51 cases. The French Study Group for HIV-Associated Tumors. Hum Pathol. 1997;28(3):367-74. [PubMed: 9042803].

10. Chamberlain MC, Kormanik PA. AIDS-related central nervous system lymphomas. J Neurooncol. 1999;43(3):269-76. [PubMed: 10563433]

11. Rosenblum ML, Levy RM, Bredesen DE, So YT, Wara W, Ziegler JL. Primary central nervous system lymphomas in patients with AIDS. Ann Neurol. 1988;23 Suppl:S13-6. [PubMed: 2894803].
12. Schabet M. Epidemiology of primary CNS lymphoma. J Neurooncol. 1999;43(3):199-201. [PubMed: 10563423].

13. Herrlinger U, Schabet M, Bitzer M, Petersen D, Krauseneck P. Primary central nervous system lymphoma: from clinical presentation to diagnosis.J Neurooncol. 1999;43(3):219-26. [PubMed: 10563426].

14. Herrlinger U. Primary CNS lymphoma: findings outside the brain. $J$ Neurooncol. 1999;43(3):227-30. [PubMed: 10563427].

15. Braus DF, Schwechheimer K, Muller-Hermelink HK, Schwarzkopf G Volk B, Mundinger F. Primary cerebral malignant non-Hodgkin's lymphomas: a retrospective clinical study. J Neurol. 1992;239(3):117-24. [PubMed: 1573413].

16. Fine HA, Mayer RJ. Primary central nervous system lymphoma. Ann Intern Med. 1993;119(11):1093-104. [PubMed: 8239229].

17. Gelabert GM, Castro BD, Serramito GR, Frieiro DC, Aran EE. Primary central nervous system lymphoma. Neurología (English Edition). 2013;28(5):283-93. doi: 10.1016/j.nrleng.2012.04.015.

18. Kiewe P, Fischer L, Martus P, Thiel E, Korfel A. Primary central nervous system lymphoma: monocenter, long-term, intent-to-treat analysis. Cancer. 2008;112(8):1812-20. doi: 10.1002/cncr.23377. [PubMed: 18318432].

19. Makino K, Nakamura H, Kino T, Takeshima H, Kuratsu J. Rising incidence of primary central nervous system lymphoma in Kumamoto, Japan. Surg Neurol. 2006;66(5):503-6. doi: 10.1016/j.surneu.2006.05.055. [PubMed: 17084198].

20. Rubenstein J, Ferreri AJ, Pittaluga S. Primary lymphoma of the central nervous system: epidemiology, pathology and current approaches to diagnosis, prognosis and treatment. Leuk Lymphoma. 2008;49 Suppl 1:43-51. doi: 10.1080/10428190802311441. [PubMed: 18821432].

21. Zali A, Shahzadi S, Mohammad-Mohammadi A, Taherzadeh K, Parsa K. Cerebral lymphoma: clinical and radiological findings in 90 cases. Arch Iran Med. 2007;10(2):194-8. [PubMed: 17367223].

22. Bhagavathi S, Wilson JD. Primary central nervous system lymphoma. Arch Pathol Lab Med. 2008;132(11):1830-4. doi: 10.1043/1543-2165132.11.1830. [PubMed: 18976024].

23. Kuker W, Nagele T, Korfel A, Heckl S, Thiel E, Bamberg M, et al. Primary central nervous system lymphomas (PCNSL): MRI features at presentation in 100 patients. J Neurooncol. 2005;72(2):169-77. doi: 10.1007/s11060-004-3390-7. [PubMed: 15925998].

24. Bataille B, Delwail V, Menet E, Vandermarcq P, Ingrand P, Wager M, et al. Primary intracerebral malignant lymphoma: report of 248 cases. J Neurosurg. 2000;92(2):261-6. doi: 10.3171/jns.2000.92.2.0261. [PubMed: 10659013]

25. Eichler AF, Batchelor TT. Primary central nervous system lymphoma: presentation, diagnosis and staging. Neurosurg Focus. 2006;21(5):E15. [PubMed: 17134117]. 